\title{
The Role of Colonoscopy in the Prevention of Colon and Rectal Cancer
}

\author{
David Martínez Ares and Pamela Estévez Boullosa \\ Gastroenterology Unit. Complejo Hospitalario Universitario de Vigo, Vigo-Pontevedra \\ Spain
}

\section{Introduction}

Colorectal cancer (CRC) is one of the most common tumors in our society. It is the most common gastrointestinal tumor and it is also estimated that between 5 and $6 \%$ of the population will suffer this tumor along their lives. Colorectal cancer is a tumor in which it is possible to perform primary and secondary prevention. It ranks second in frequency in both men and women, and it represents the second leading cause of cancer-related deaths in both men (after lung cancer) and women (after breast cancer). Indeed, CRC is responsible for $12 \%$ of cancer-related deaths in men and for $15 \%$ in women. It represents, therefore, a public health problem of first magnitude, causing over 10,500 annual deaths in Spain; so it is well established and cost effectiveness to use a program for early detection and prevention of this disease. CRC mortality in 2006 was almost double that the one recorded in Spain in 1975 in both sexes, considering them separately, and in the entire population as a whole. In relation to the rest of the Europe, Spain has an intermediate CRC mortality, lower than that recorded in Czech Republic or Slovakia, and well above from CRC mortality in Finland or Cyprus. In Spain, cancer mortality is higher in the north than in the south, and this difference is more significant in males. Furthermore, cancer mortality in the whole country is quite stable since the beginning of this century, observing a slight increase in northern regions.

The survival of patients diagnosed with CRC is approximately $54 \%$ at 5 years after diagnosis. However, survival is significantly lower in the group of patients in advanced stages, and much higher, with a survival rate around $90 \%$, when it comes to patients in early stages. Therefore, an early diagnosis of colorectal cancer can lead to a significant reduction in cancer mortality. Consequently, a program of screening or early detection could considerably improve the prognosis of this disease.

Colorectal cancer is a health problem that fulfills all the requirements that the World Health Organization requires to consider a cost-effective screening program for early detection of neoplasia: first it is a very common disease, representing a major public health problem; second it is a disease with a well-known natural history, fulfilling in most cases the adenoma-carcinoma sequence (Figure 1), and this natural history is long enough so it can be interrupted by various diagnostic and therapeutic strategies; thirdly, we have diagnostic methods with enough diagnostic accuracy and at reasonable cost; fourthly, there is an effective treatment and, finally, this approach seems to be cost-effective. However, these screening programs have been implemented in very few sites in the world, having to be reduced in many cases to opportunistic screening or, at best, reduced to population at 
highest risk of developing the disease, such as those suffering from predisposing diseases such as ulcerative colitis, or individuals with high familial risk of developing the disease.

There is little doubt about the beneficial of a program for early detection of colon cancer: the diagnosis of the disease in an early stage practically ensures its cure, and even in many cases, we will be able to diagnose precancerous lesions and removing them we can avoid the appearance of cancer. The best prevention strategy is subject of discussion, especially in lower-risk patients.

As expected, before proposing an individual for inclusion in a screening program it is essential to establish their individual risk of developing colon cancer. Routinely, the population is divided into three groups according to their risk of developing colorectal cancer (CRC):

- Low-risk population: includes individuals younger than 50 years, without personal or family risk factors for developing CRC. In this population is not recommended CRC screening.

- Average-risk population: they are people whose only risk factor for the condition of the disease is having an age over 50 years. Given the high incidence of the disease after this age, it is justified to perform an early diagnosis.

- High-risk population: includes all individuals with personal risk factors (history of polyps or colorectal cancer or predisposing conditions such as inflammatory bowel disease) or family risk factors for cancer development. It is well known that the existence of first-degree relatives of colon cancer increases the risk for the disease; in addition, there are familial forms of cancer or hereditary syndromes (familial adenomatous polyposis and hereditary non-polyposis colorectal cancer are the most common).

\section{Adenoma-Carcinoma Sequence}

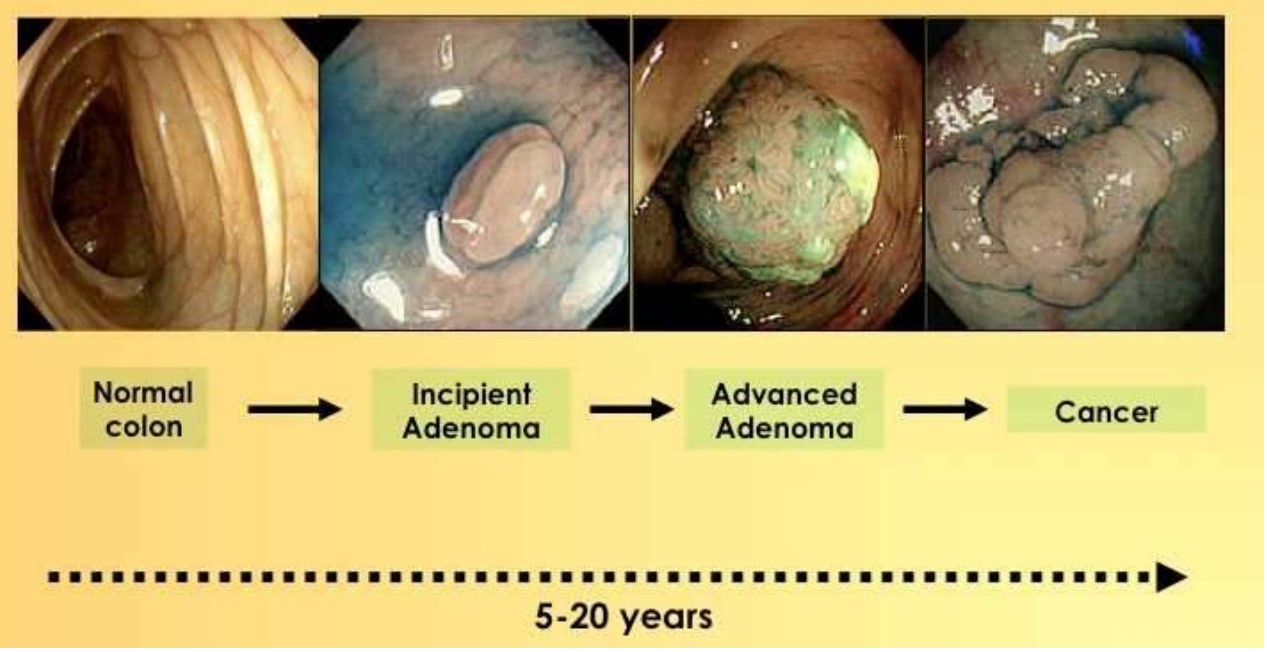

Fig. 1. Adenoma-carcinoma sequence represents the evolution of most colorectal carcinomas, from a normal colon to the development of an invasive carcinoma 


\section{The role of colonoscopy in preventing colorectal cancer}

Colonoscopy plays a dual role in preventing colorectal cancer. First, endoscopic examination of the colon and rectum is the gold standard in the diagnosis of neoplastic and preneoplastic lesions in the large intestine. On the other hand, the development of therapeutic techniques such as polypectomy or more complex techniques like endoscopic mucosal resection or endoscopic submucosal dissection, allows the removal of some of these lesions. Indeed, endoscopic resection is curative in almost all preneoplastic lesions (benign lesions) and may be curative in early malignant lesions, which are those that only affect the mucosa and submucosa.

Colonoscopy is useful for the diagnosis of cancer and precancerous lesions. Unquestionably, despite radiological techniques are useful for diagnosis, the role of colonoscopy is essential firstly to confirm the radiological findings and also to obtain biopsy specimens for histological diagnosis. Colorectal cancer is frequently presented as proliferative lesions that produce some stenosis of the intestinal lumen, with ulcerated surface and even with hemorrhagic necrotic areas (Figure 2); sometimes they are polypoid lesions that can also have ulcerated areas (Figure 3), or just be circumscribed ulcerations (Figure 4).

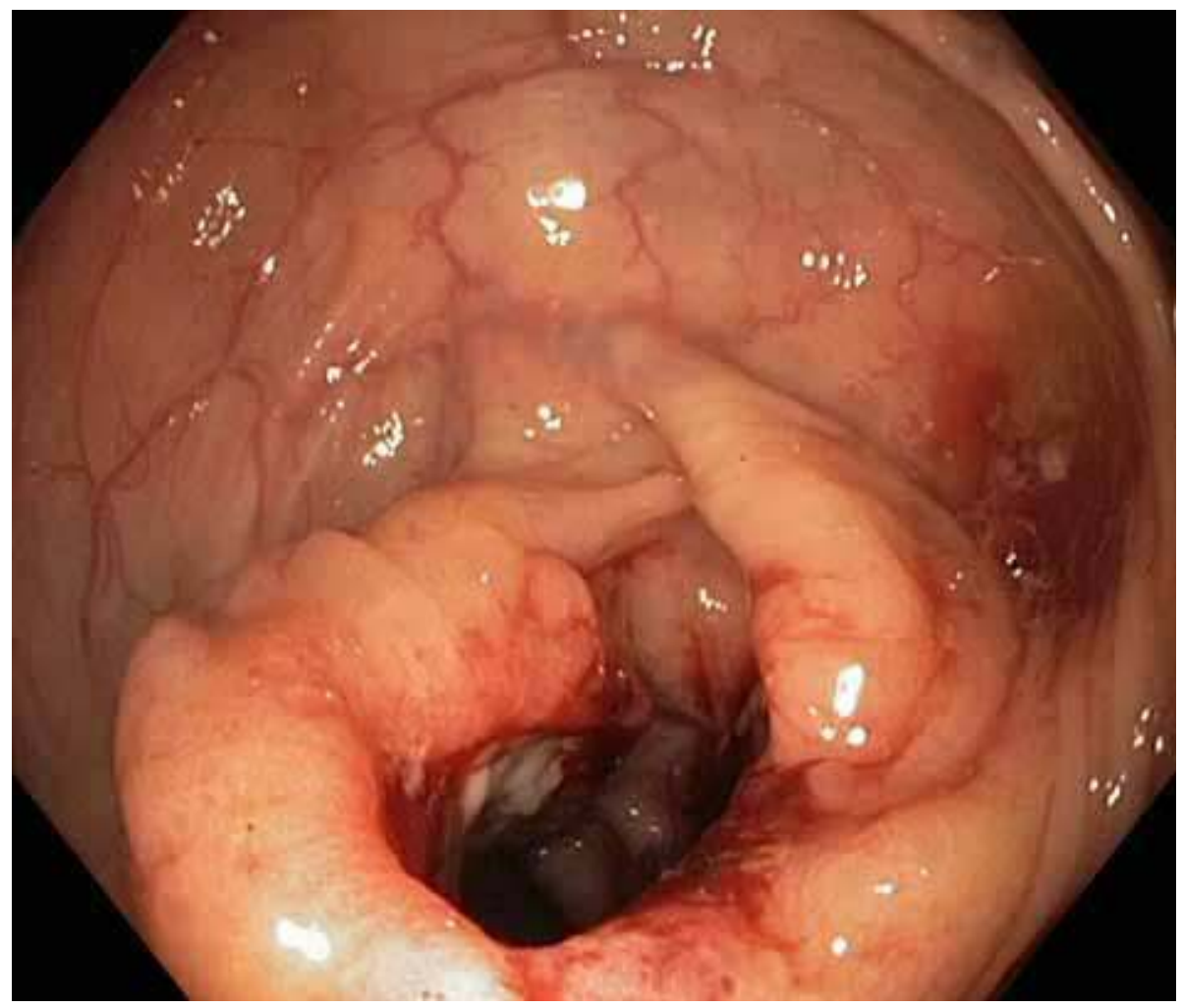

Fig. 2. Malignant lesion covering the entire circumference that produces stenosis of the intestinal lumen, with ulcerated surface, hemorrhagic necrotic areas and bleeding easily at the touch of endoscope 


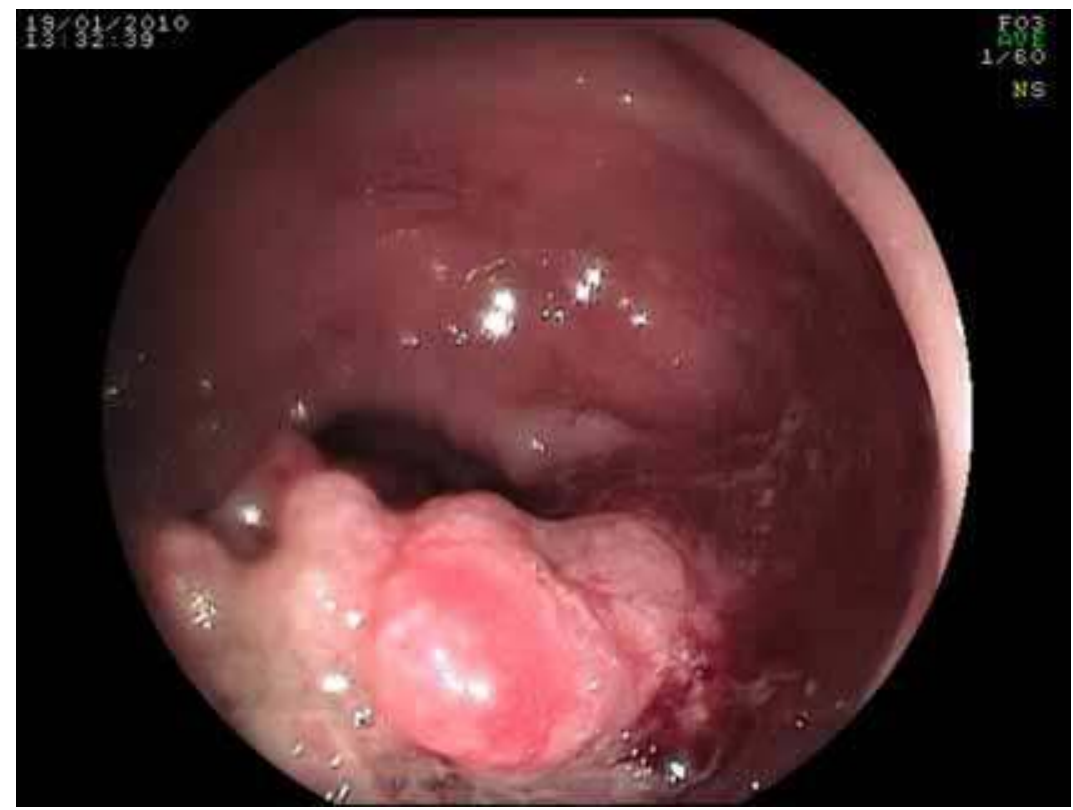

Fig. 3. Sessile polyp, with wide-based attachment, embossed surface, with ulcerated areas and a friable mucosa. Biopsies from the lesion suggest adenocarcinoma arising in a villous adenoma

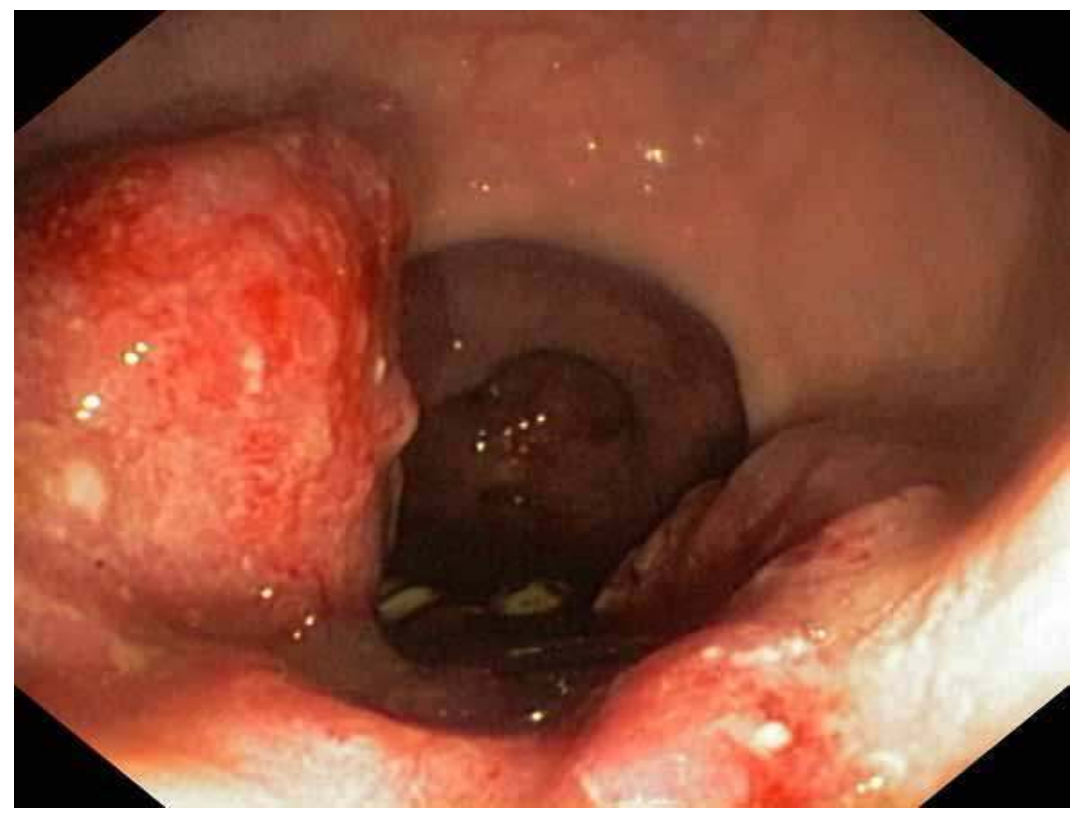

Fig. 4. Ulcer that affects 2 / 5 parts of the circumference of intestinal lumen, with raised and indurated edges. Biopsies suggested undifferentiated adenocarcinoma 


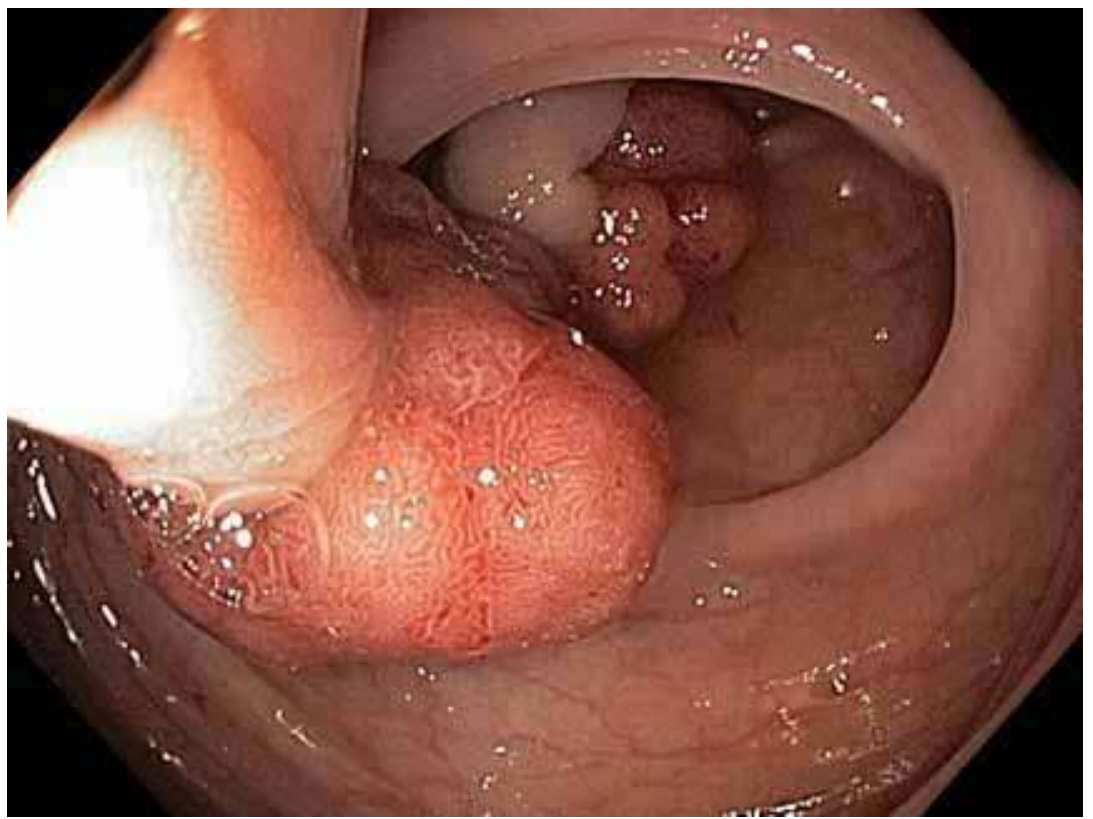

Fig. 5. The picture shows two large pedunculated polyps. Adenomatous tissue is easily differentiated from the pedicle, consisting of normal mucosa, non-neoplastic

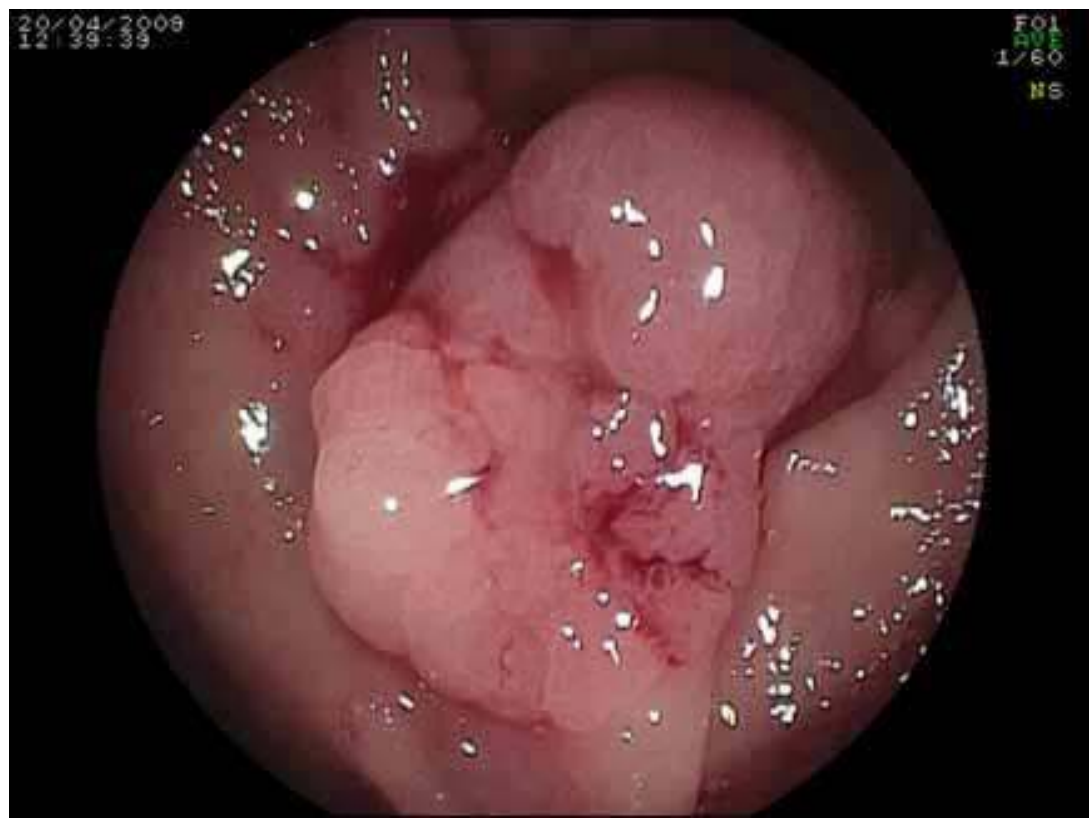

Fig. 6. Sessile polyp, with wide-based attachment, in which it does not recognize any pedicle 
The diagnosis of polyps is also quite distinctive, as outgrow ths on the colonic mucosa with variable size and morphology. They can present as pedunculated lesions (Figure 5), sessile lesions (Figure 6), or as flat or very slightly raised lesions (Figure 7). Occasionally, lesions can be almost undetectable during a conventional colonoscopy, so some special techniques such as chromoendoscopy or modern techniques of Narrow Band Imaging and Computed Virtual Chromoendoscopy can be helpful to identify and study the lesions more accurately (Figure 8). After these lesions have been located and characterized, we should think in the possibility to perform the resection of the lesion by polypectomy (Figure 9) or endoscopic mucosal resection (Figure 10).

Although, in general, the role of colonoscopy in preventing CRC can be summarized in the above, there are some differences in the groups of patients that have been differentiated according to their risk of developing the disease. For this reason, then we will discuss in greater detail, the place of colonoscopy in the screening strategies proposed for each of these patients.

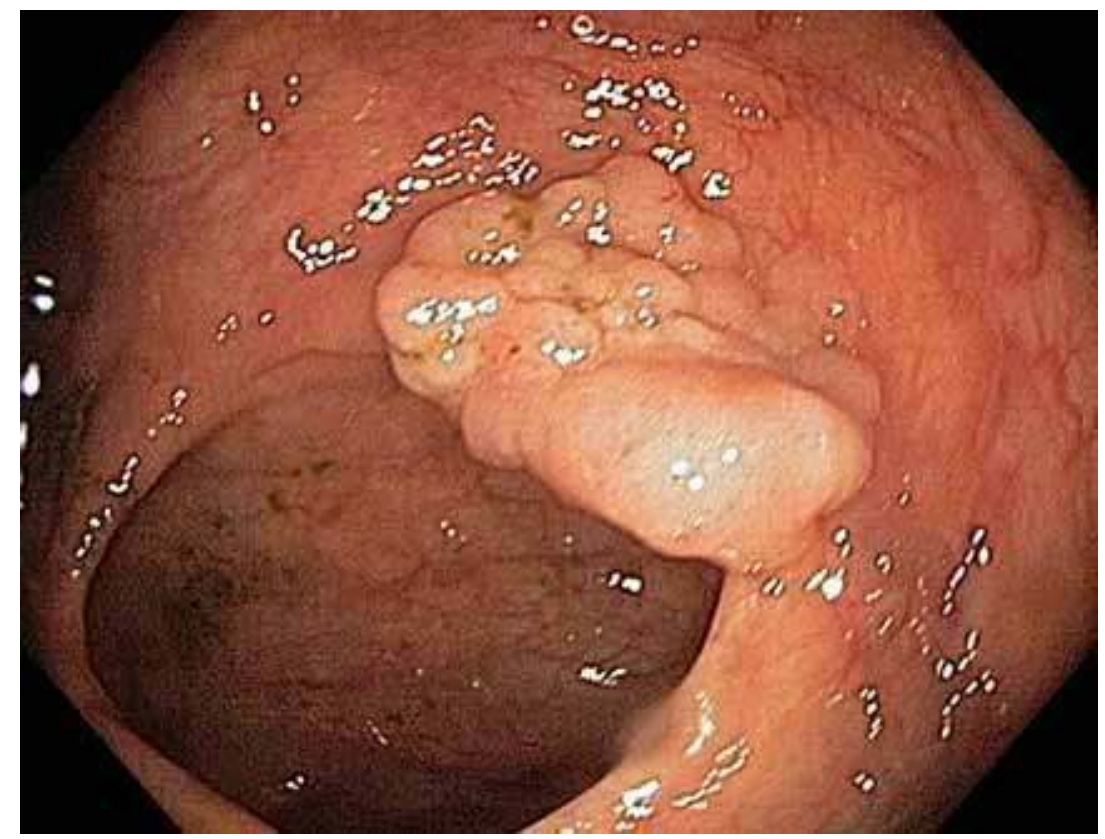

Fig. 7. Flat polyp, located in right colon close to the ileocecal valve. The lesion has a thickness of a few millimeters and a granular surface

\subsection{Usefulness of colonoscopy in preventing CRC in average risk population}

This is the largest group of individuals who would be subsidiaries of CRC prevention programs, so the group would consume a greater amount of resources. In fact, most colorectal carcinomas are sporadic, appearing in patients who have neither family history of disease or conditions predisposing to disease.

The prevention strategy that arises in this population is, once assumed the failure of primary prevention, it takes place secondary prevention. That is, it is an early diagnosis of cancer or 


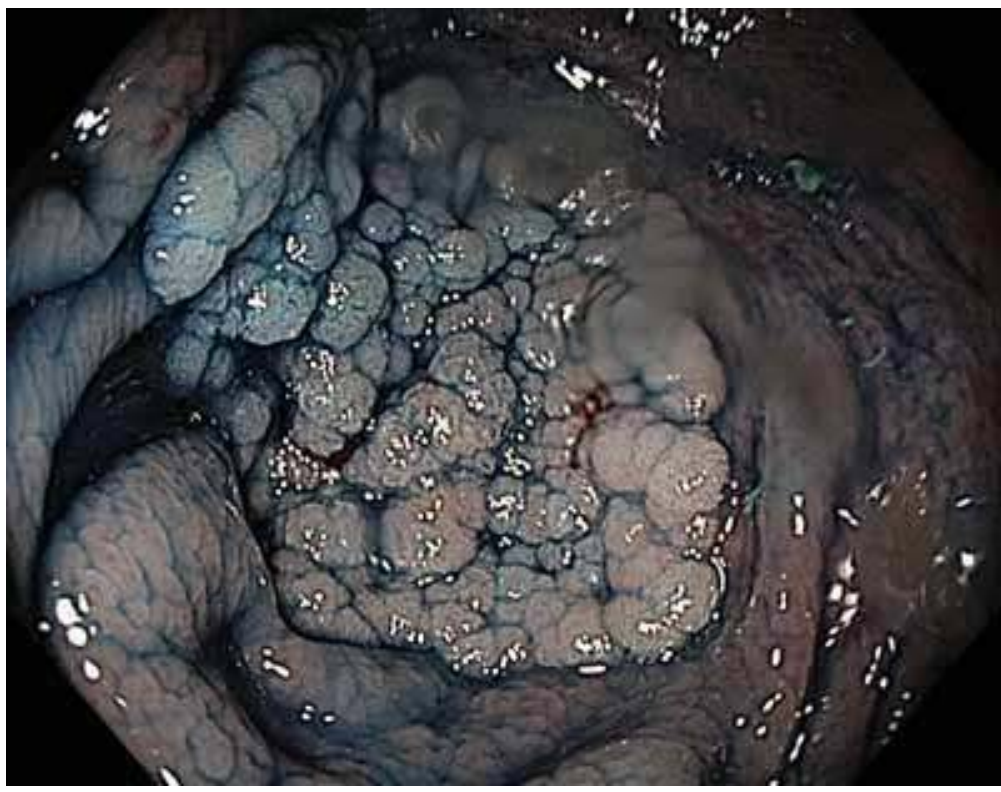

Fig. 8. Laterally spreading tumor with granular surface, with sharply demarcated edges after performing vital staining with indigo carmine $2 \%$

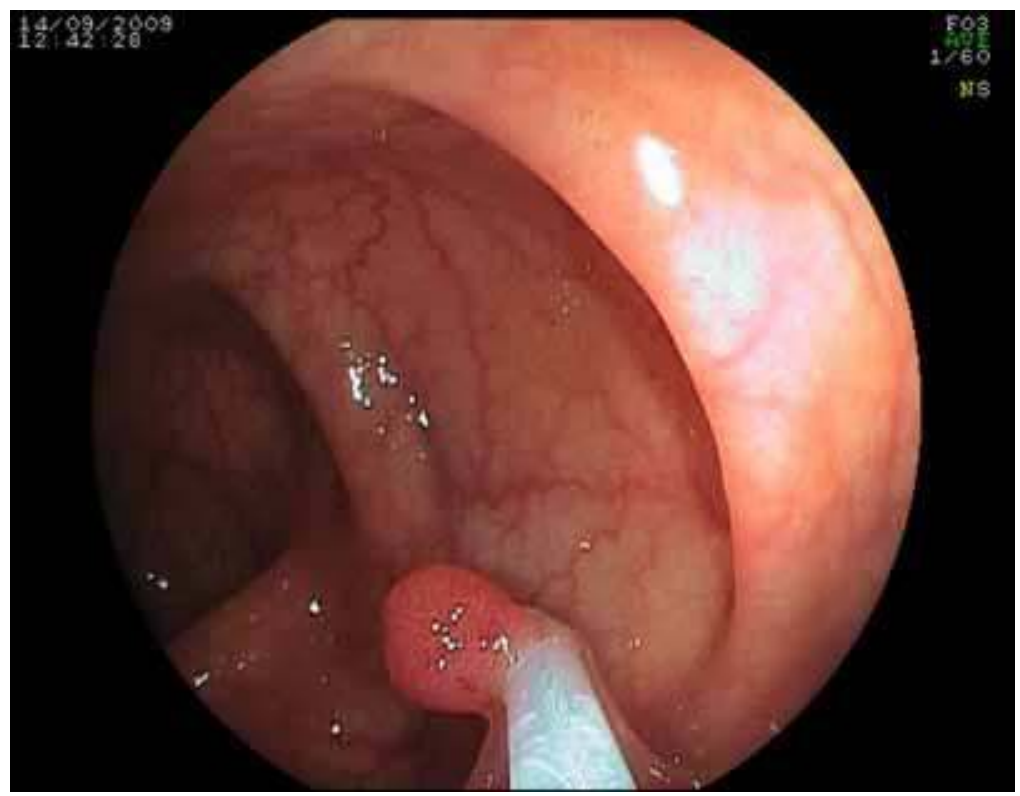

Fig. 9. Endoscopic polypectomy by polypectomy snare of a pedunculated lesion of about 7 $\mathrm{mm}$ in diameter, located in proximal transverse colon. The pathological study revealed the presence of a tubular adenoma with low grade dysplasia 
precancerous lesions, in order to ensure a treatment with the best outlook for cure. In the case of diagnosis of polyps, colonoscopy and polypectomy allow the resection of the lesions and, thus, to prevent the occurrence of CRC.

In this group the screening strategies accepted and recommended by different international and Spanish scientific societies are:

- Fecal occult blood, immune test preferably (FOBT), on an annual or biennial periodicity.

- $\quad$ Barium enema, replaced in most developed countries by the CT-colonography, every 5 years.

- $\quad$ flexible sigmoidoscopy every 5 years

- total colonoscopy, every 10 years

No comparative studies are available that allow us to establish which is the most cost effective strategy. Taking into account that the most questionable option is represented by radiological tests, it seems that the discussion focuses on the choice of test FOBT or colonoscopy. If we accept the numbers described in several studies, stating that, in patients at average risk, adenomas should be detected in at least $25 \%$ of screening colonoscopies, there are doubts about the profitability of the radiological techniques. However, at present, we do not have enough scientific evidence to choose any strategy, although there is an American study which points in this direction. In Spain it is estimated that the cost per year of life saved using immunological fecal occult blood annually is around $€ 1,200$, and it is $€$ 2,300 for sigmoidoscopy every 5 years or colonoscopy every ten years. Both cases demonstrate the low cost of these screening programs when we compared them with other established screening systems for other malignancies such as cervical or breast cancer, whose cost is approximately 5-6 times higher.

The screening of colorrectal cancer in average risk population implies a significant increase in the number of colonoscopies that we must perform in our units. There are some concers about this situation. Perharps, there are no enough endoscopists in our health system to answer this raising demand of colonoscopies. The spanish health system should consider this limitations before the implementation of a screening program.

\subsection{Prevention of colorrectal cancer in patients with personal history of polypectomy or CRC}

Patients in which colonic polyps were removed or that have been treated for colon cancer should be included in specific monitoring systems. So this is tertiary prevention, and the aim is to detect metachronous lesions that appear in the months or years after the onset of the initial lesion. This disclosure is based on the possibility that the patient could have synchronic small lesions that could have not been detected in the initial colonoscopy. When performing a new examination in a reasonable period of time, these lesions would be detected in early stages yet. On the other hand, it is also known that these patients have an increased risk of presenting new lesions in the future. The only test accepted by all societies for these patients is colonoscopy.

The frequency of follow-up colonoscopies will be determined by the type of lesions presented by the patients. Naturally, any recommendation is based on the fundamental principle that colonoscopies performed meet all the standards of quality: good bowel preparation, full colon examination and mean colonoscopic withdrawal times of at least 6 minutes. In fact, all the factors mentioned above, especially the last one, are significantly correlated with the rate of polyps detected at screening colonoscopy. 


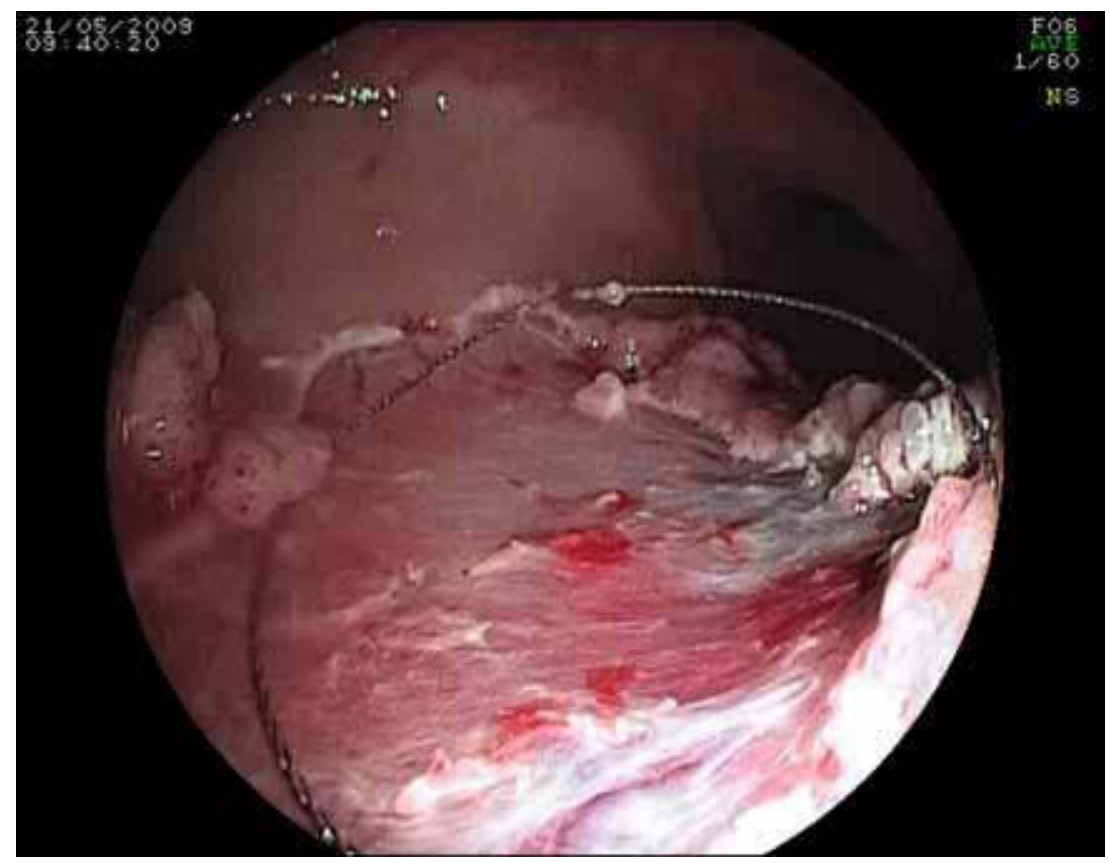

Fig. 10. Picture showing endoscopic mucosal resection of a large flat polyp placed in rectum. The size of the polypectomy snare allows us to approximate the size of the lesion, which is about twice the size of it, so about $6 \mathrm{cms}$. The resection is performed gradually, in several fragments (piecemeal resection). By this way large lesions can be removed

The number and characteristics of the resected polyps are, therefore, the key factors to establish the date of the next examination. The existence of multiple adenomas (more than three) or a polyp that has a size greater than $10 \mathrm{~mm}$ or, regardless of size, the polyp has a villous component or high grade dysplasia (advanced adenoma); leads to set the following colonoscopy within three to five years. If the number of adenomas removed is larger than 10 , we recommend surveillance colonoscopy within less than 3 years. When these conditions are not are satisfied (less than three adenomas, without advanced adenoma characteristics), the next examination should be done within five to ten years. In case of a first surveillance examination without evidence of new adenomas, subsequent colonoscopies should be performed every 5 years.

In patients who have been treated for colorectal cancer, as well as in patients with adenomas, we should have a complete study of the colon before surgery or at least within 6 months. In case of obstructive tumors in which it is impossible to complete a study by colonoscopy, we can complete the examination of the colon with a CT-colonography. Most clinical practice guidelines recommend a review of the surgical anastomosis within one year after the intervention, to rule out a possible anastomotic recurrence and then, the recommendations are the same as those for patients undergoing endoscopic polypectomy: the first examination after three years and the following ones, if not metachronous lesions were detected, should be performed at intervals of 5 years. In case of detecting lesions during follow-up, its features will condition the surveillance. 


\subsection{CRC screening in patients with inflammatory bowel disease}

People suffering from inflammatory bowel disease, especially ulcerative colitis have an increased risk of colon cancer. The risk is only increased in patients with extensive disease, thus it is not indicated endoscopic surveillance in patients with ulcerative colitis that only affects the rectosigmoid region. However there are a number of factors that are associated with a significant rise in the incidence of colon cancer. Indeed, the risk increases significantly if there are family history of colon cancer, if primary sclerosing cholangitis is associated with ulcerative colitis and, undoubtedly, if it is a disease with difficult control with persistent inflammation and presence of inflammatory pseudopolyps. Patients with Crohn's disease with extensive colonic involvement may also have an increased risk of developing colon cancer, so surveillance should also be extended to this group of patients.

The risk increases significantly after 8-10 years of development, being that the moment in which it is recommended to start the monitoring programs. Naturally, and taking into consideration that what we are looking for is the presence of dysplasia, colonoscopy with biopsy of colorectal mucosa is the only valid screening strategy. However, the evidence supporting this colorectal cancer screening is poor. Several studies suggest that the inclusion of patients in screening programs improves the prognosis of the disease because many cases would be diagnosed in early stages. In contrast, other studies doubt about the utility of specific screening programs, since most malignancies would be diagnosed as interval cancers. Although scientific evidence is little and poor, the majority of international clinical practice guidelines, and also guidelines available in Spain, recommend to start with screening from 8-10 years after development of the disease in extensive colitis, and from 15 years in colitis that just involve the left colon. As explained before, it is not justified to perform any kind of endoscopic screening in patients with only rectal involvement. Initially it would be recommended to perform colonoscopy every 2-3 years, and then to increase in frequency because the incidence of colon cancer increases with duration of disease. It has been suggested to perform colonoscopies every two years after 20 years since the diagnosis of the disease and annually after 30 years of development of ulcerative colitis. It is also included in most guidelines the recommendation to intensify surveillance in patients with sclerosing cholangitis due to its association with an increased risk of CRC, indicating to perform an annual colonoscopy at the time of diagnosis of primary sclerosing cholangitis.

The best way to prevent the appearance of colon cancer is an early detection of dysplasia. Therefore, we should carefully explore all of the colon mucosa, trying to detect any mucosal lesion (minimum mucosal elevation, polyp, mass ...) and if so, we should take biopsies. Additionally, biopsies from the entire colonic mucosa should be systematically taken and the most widely recommendation accepted is taking 4 biopsy specimens every $10 \mathrm{~cm}$ of intestine. As expected, the examinations are hardworking and, with the available evidence, we can not ensure its cost effectiveness. In order to make these examinations less timeconsuming and possibly more cost effective, several studies propose to take biopsies in a targeted way, using magnification endoscopy and chromoendoscopy. Thus, these techniques help us to choose the areas that we need to biopsy, and this could probably improve the detection of dysplasia and also they can help us in reducing the number of biopsies that should be taken. At the present time confocal endomicroscopy is under study. This technique allows subsurface histological diagnosis in situ, without taking biopsies, and it could probably be more helpful detecting dysplasia. However, these are very long examinations, and this technique requires an expensive technology and a specialized training by the endoscopist, so it becomes a technique restricted to highly specialized centers. 
There is some agreement on the way to approach after detecting dysplasia. Due to the high incidence of synchronous adenocarcinoma with high-grade dysplastic foci, it is usually recommended to perform a total proctocolectomy after detecting high-grade dysplasia. In case a low-grade dysplasia, the decision is more controversial. If multiple foci of dysplasia on flat mucosa are detected, it is recommended to perform a proctocolectomy. On the other hand, if isolated foci of dysplasia are detected the recommendation should be to perform a new colonoscopy within approximately 3-6 months. Subsequently, following colonoscopies should be performed every 6 months.

Elevated lesions or masses can appear in patients with ulcerative colitis, and in many cases they are similar to adenomas. The presence of dysplasia on these raised lesions causes a difficult differential diagnosis with sporadic adenomas that are defined by the presence of dysplasia and whose treatment could be endoscopic polypectomy. Generally, we consider dysplasia-associated lesion or mass (DALM) if the lesion is located on "colitic" mucosa (even in quiescent ulcerative colitis), while if it appears on normal mucosa, it is probably sporadic adenoma. Sporadic adenoma should be treated as in the general population and DALM could also be endoscopically removed after ruling out the presence of dysplastic lesions in the surrounding mucosa. If this is not technically possible or perilesional mucosal biopsies present dysplastic foci, we should perform a total colectomy. If we have performed endoscopic resection of the lesion, we should take biopsies of the mucosa around the lesion in 3-6 months, and also the following colonoscopies should be performed every six months. The work for pathologist is not always easy and he can find cases in which, mainly due to the persistence of inflammatory activity, the findings are not definitive to confirm or exclude dysplasia. In these cases, endoscopy should be repeated within 3-6 months after an appropriate control of mucosa inflammation under a specific treatment.

As presented, colonoscopy is essential in monitoring these patients, being the only tool that allows taking biopsies to detect dysplasia. However, there is a long way to walk until we find the ideal strategy to make examinations less time-consuming and more cost effective. Everything suggests that modern endoscopic techniques (magnification endoscopy and chromoendoscopy) can be the key, but there is little scientific evidence by now. Secondly, the steps to follow in case of dysplasia seem to be more established. Finally, colonoscopy may have a therapeutic role if we detect low-grade dysplastic foci on lesions and masses similar to adenomas.

\subsection{Colorectal cancer screening strategies in patients with family history of CRC}

The risk of colorectal cancer is higher in those people who belong to families where cases of CRC have been recorded, even after having ruled out the possibility of polyposis syndromes and hereditary colorectal cancer. How ever, the risk depends on several factors: the number of relatives affected, the degree of kinship and age at which the neoplasm is detected. In second-degree relatives, excepting they were multiple family members affected, it is not justified any special CRC screening, and the recommendations are the same as for mediumrisk population. In case of multiple second-degree relatives affected, the different scientific societies recommend the same screening strategy as for people at average risk, but starting the screening program at age 40 years. In case of several first-degree relatives or a single family member younger than 60 years at the time of diagnosis, the only recommendation accepted is to perform colonoscopy every five years. The age to start the screening will be at 40 years of age or at age 10 years younger than the youngest case diagnosed in the family. The presence of a single first-degree relative older than 60 years increases the risk of 
developing the disease but in a lesser way, so the recommendations are the same as if there were second-degree relatives affected.

In summary, if there is a family history of colorectal cancer, the risk is increased respecting to the average risk population. If there is a low risk family history, as well as medium-risk population, the acceptable screening tests include fecal occult blood testing, colonoscopy and radiological tests. By contrast, if there is a high risk family history the only accepted screening test is colonoscopy because there are higher possibilities of detecting cancer or polyps.

\subsection{Hereditary CRC syndromes: non-polyposis colorectal cancer and familial adenomatous polyposis}

\subsubsection{Hereditary non-polyposis colorrectal cancer or Lynch syndrome}

Hereditary non-polyposis colorectal cancer (HNPCC) or Lynch syndrome is an autosomal dominant disease which represents less than $2 \%$ of total CRC. It is mostly due to mutations in DNA repair genes and, clinically, it is characterized by the development of neoplasia in young people (under 50 years) with high preference for right colon, with great tendency to develop synchronous and metachronous neoplasms as well as in other organs (urinary tract, biliary tract, endometrium, pancreas, stomach, small intestine and ovary). It is more uncommon to find development of osteomas, skin or brain tumors. Pathologically it is characterized by a strong tendency to present a mucinous histology.

The diagnosis is based on the Amsterdam criteria: at least three relatives affected, one of whom is a first degree relative of the other, at least two successive generations involved and at least one case diagnosed of cancer before age 50 . Then, these criteria were found to be too strict and were expanded to include the associated non-colorectal cancers (Amsterdam II). In any case, these criteria have poor sensitivity for the diagnosis of the disease, although its specificity is very high. Therefore, the Bethesda criteria were established, suspecting the disease by demonstrating on the resected tumor the presence microsatellite instabilty (expression of mutations in repair genes). It is mandatory to perform a genetic analysis whether if diagnosis is based on the Amsterdam criteria or on the analysis of microsatellite instability. If the mutation responsible for the disease is detected in a patient, the family members should be studied, and only those who file such mutations will be subsidiary to perform the screening program.

The aim of endoscopic surveillance of people belonging to families with Lynch syndrome is the early detection of cancer or polyps and their removal when it is possible. In many cases, precancerous lesions are flat lesions, and may not be detected by non-endoscopic techniques, so the only acceptable diagnostic technique for monitoring is the colonoscopy. Even these lesions are difficult to detect with conventional endoscopy, which may explain the high frequency of interval cancers. For this reason it was suggested to use more sophisticated endoscopic techniques (Narrow Band Imaging and chromoendoscopy) to facilitate the detection of these lesions. In our experience, chromoendoscopy seems to be easier to perform and to interpret. To do it, it is essential a correct colon cleansing and staining of the colonic mucosa with a solution of Indigo Carmine $0.2 \%$. This will significantly improve the detection of flat lesions, almost imperceptible by conventional colonoscopy. The use of magnification endoscopy can further improve diagnostic accuracy. Computed virtual chromoendoscopy (CVC or FICE, Fujinon) (Figure 11) can be an alternative to conventional chromoendoscopy (Figure 12), avoiding the use of colorants and making even shorter examinations, but of course, it depends on the availability of this technology. The use of NBI (Figure 13) may be helpful for the characterization of lesions, but this technique may be more complicated than chromoendoscopy. 


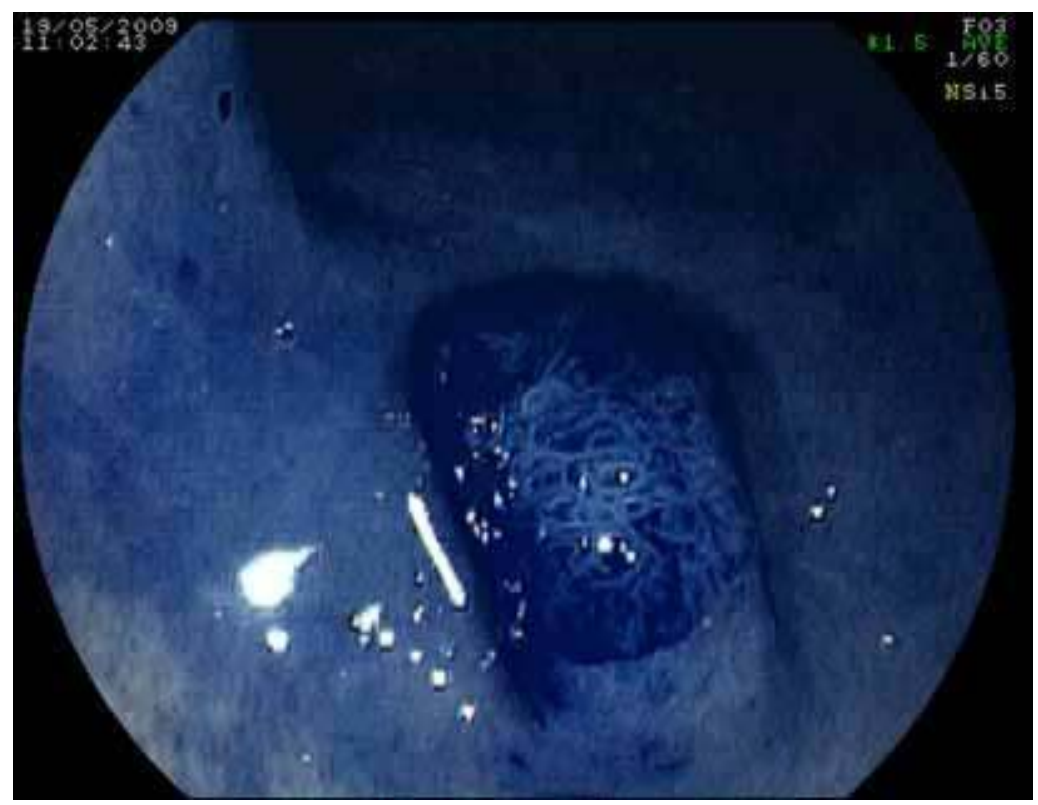

Fig. 11. Flat lesion in the right colon in a patient with quiescent ulcerative colitis, studied by CVC, Set 4

The interval between examinations in these cases is determined by finding the adenomadysplasia-carcinoma progression significantly shortened or even that it does not exist. It has been shown that performing examinations every 3 years had managed to reduce the incidence and the CRC mortality in more than $60 \%$. However, widespread recommendations propose to perform colonoscopies every 1 or 2 years. Patients operated on for CRC in the context of Lynch syndrome have a high possibility of metachronous lesions, so post-resection surveillance recommendation is the same as the screening strategy for relatives at risk. The age at onset of endoscopic surveillance is usually established around 20-25 years of age or 10 years younger than the youngest case in the family, choosing the option that happens before. In conclusion, in people from families with Lynch syndrome it is justified to perform surveillance programs. The only acceptable alternative is to conduct endoscopic surveillance and, based on current evidence, conventional endoscopy may not be sufficient. The use of chromoendoscopy and magnification endoscopy may be useful, so monitoring of these patients should be performed in specialized endoscopy units with endoscopists trained in these techniques.

\subsubsection{Familial adenomatous polyposis}

The classic form of familial adenomatous polyposis (FAP) is characterized by the development of hundreds of polyps in the colon, usually after puberty. Its pattern of inheritance is autosomal dominant and in the absence of surgical treatment, $100 \%$ of patients would develop cancer. An attenuated form of familial adenomatous polyposis has been identified. Individuals with attenuated FAP develop 20-100 adenomatous polyps and the average age of diagnosis is ten years later than in the classic form. There is the possibility of developing polyps at other gastrointestinal levels or tumors in other locations. 


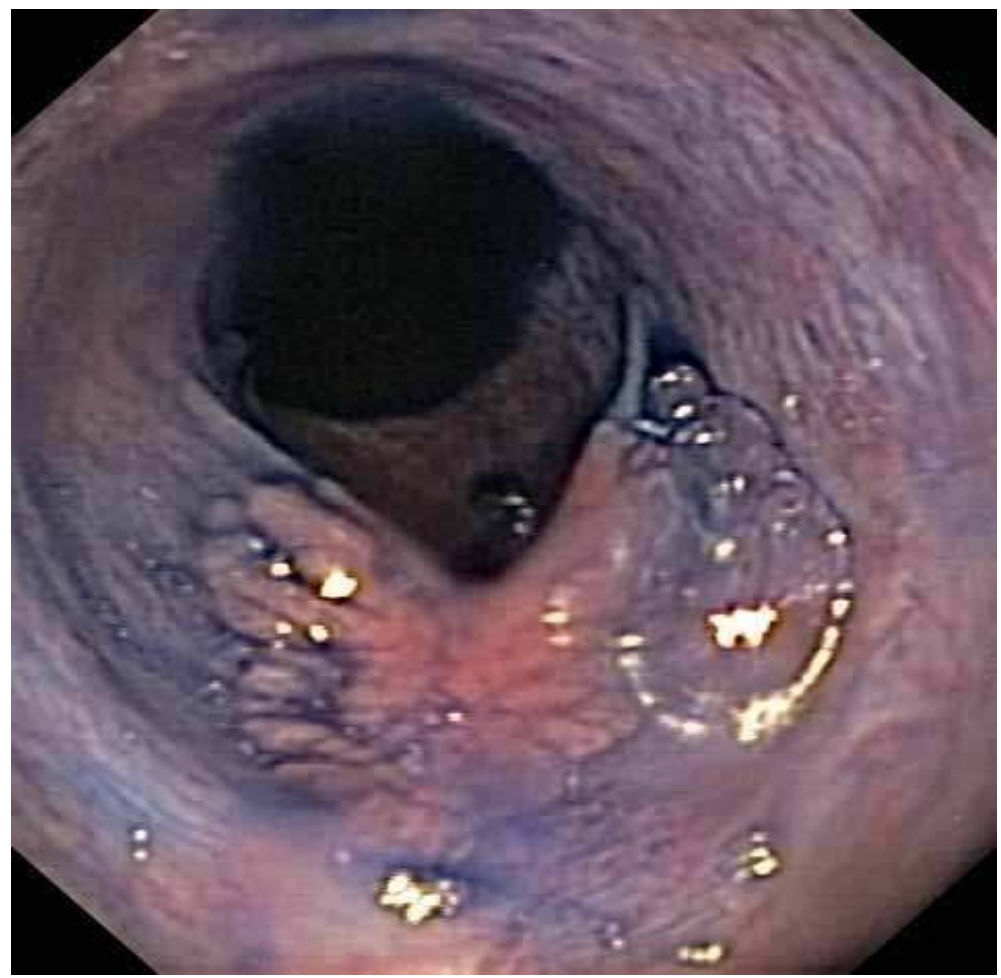

Fig. 12. Flat lesion, almost imperceptible to conventional endoscopy, which clearly demarcates with $0.2 \%$ indigo carmine. This is a patient who performed a colonoscopy as colorectal cancer screening method because he belonged to a family that fulfilled the Amsterdam criteria for diagnosing HNPCC. This is a lesion that, according to the Paris classification of superficial gastrointestinal neoplasia, can be a category $\Pi c$ (excavated or depressed). According to its size (about $25 \mathrm{~mm}$ ) endoscopic resection can not be considered. Indeed, the study of the surgical specimen showed the presence of adenocarcinoma with infiltration of the muscularis propria (pT2)

The diagnosis is based on detection of polyps by endoscopy and histologic confirmation of the presence of adenomas. Then, genetic testing should be performed to identy APC gene mutations. However, mutations are not identified up to $30 \%$ of cases. Most diagnoses occur in relatives of patients affected, who are included on endoscopic surveillance programs. The recommended strategy in most guidelines is performing sigmoidoscopy every 1-2 years from 13-15 years of age and up to 40. From this age, they are recommended every 5 years until 60 years. In attenuated FAP, screening begins at age 10 years older than in classical FAP, and as polyps are more likely to appear on the right colon, colonoscopy should be complete. Also, chromoendoscopy may improve the detection rate of polyps on these patients.

When individuals are diagnosed, prophylactic colectomy should be considered. The standard surgery is proctocolectomy with ileo-anal reservoir. In patients with reservoir, endoscopic examinations should be performed every 3 years. In patients who have 
preserved the rectum (for example in attenuated FAP it is a good option, if there are few polyps in rectum), endoscopic examination should be performed every 6-12 months.

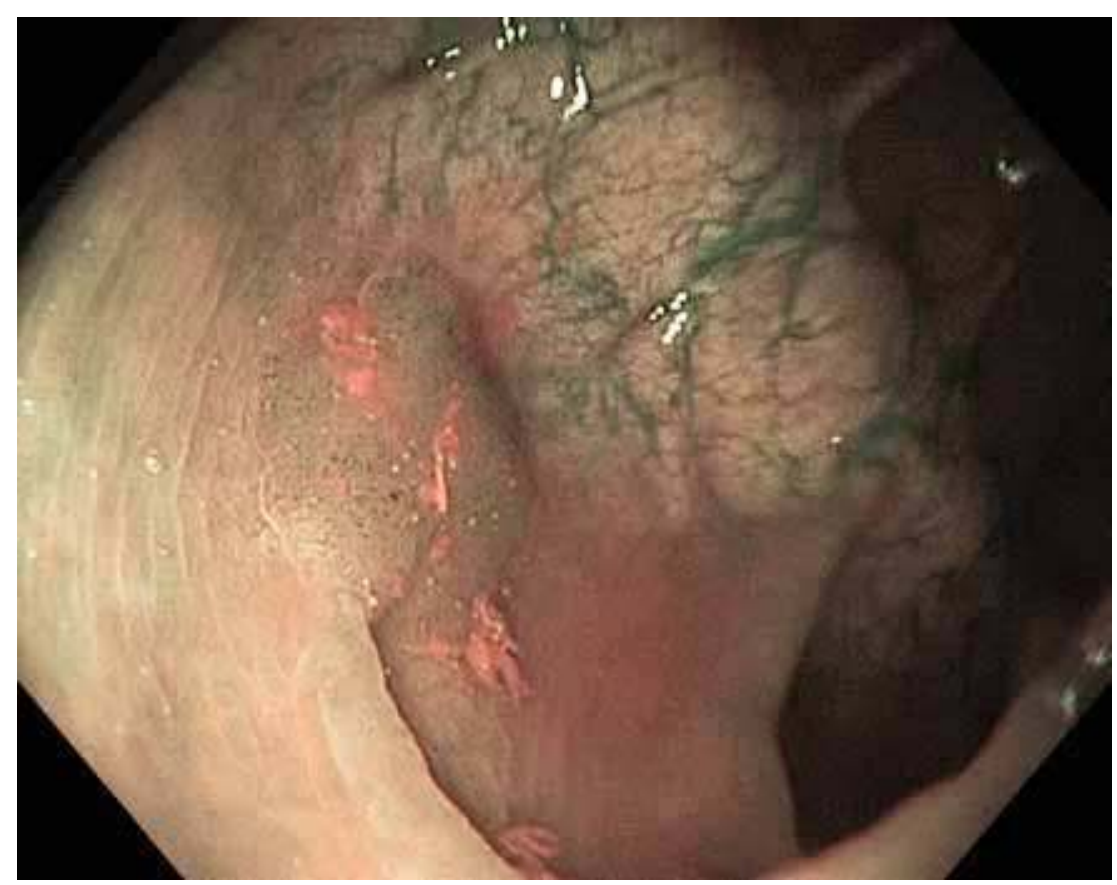

Fig. 13. Flat lesion, about $10 \mathrm{~mm}$, located in the hepatic flexure of colon, visualized with NBI. This is a Ila lesion according to the Paris classification. Endoscopic resection and histological study of it showed a villous adenoma with high grade dysplasia

Due to these patients may have adenomas in other locations of the upper gastrointestinal tract, other endoscopic procedures should be performed. It is recommended to perform a gastroscopy every 4-5 years starting from age 25. If no adenomas are detected, another possibility is to take random biopsies on the duodenal folds. Additionally, it is recommended using side vision duodenoscope for further examination of the papillary area to detect ampulomas. Treatment of duodenal adenomas is controversial. Endoscopic resection of them seems to be not very effective, especially if they are many, and it is a technique that is not exempt of complications. The severity of the lesions is established by Spiegelman classification, which takes into account the number of adenomas, size, histological type and presence of dysplasia. In patients with duodenal adenomas Spiegelman stage I-II disease, endoscopic surveillance could be performed every 2-3 years, but in patients with more complex cases, monitoring should be stricter, like performing endoscopy every 6-12 months, but probably surgical treatment should be the best option in these cases. On the other hand, endoscopic removal of the most significant adenomas could delay surgical decision.

There are some other forms of polyposis, like MYH-associated polyposis (MAP) which appears to be similar to other hereditary conditions as attenuated familial adenomatous polyposis, so screening strategies in people with MAP should be similar to screening in people with attenuated FAP. 


\section{Conclusions}

As we have explained, colonoscopy plays an important role in preventing colorectal carcinoma. In average risk populations for developing of cancer, it is one of the recommended screening strategies. In this population it has not yet been demonstrated which one is the most cost-effective strategy. What is unquestionable is the role of colonoscopy because of its therapeutic approach on the removal of lesions detected by other techniques or by its own. In high-risk populations, the only acceptable strategy is screening colonoscopy. The frequency of examinations is determined in each case by the particular risk of developing CRC. In some cases, such as patients with long-standing ulcerative colitis or individuals from families with Lynch syndrome, conventional colonoscopy is not enough, requiring using special techniques for endoscopic diagnosis, such as chromoendoscopy and magnification endoscopy.

\section{Acknowledgment}

Our thanks to Dr. Vincent Hernandez Ramirez for providing us the latest data on colorectal cancer epidemiology in our country, and to Dr. Maria Luisa de Castro Parga to transfer us some of her images. In addition, we would like to thank the whole team and staff of the Endoscopy Unit in our hospital. Without their knowledge and dedication, our work would be less productive.

\section{References}

Castells A, Marzo-Castillejo M, Mascort ש, Amador FJ, Andreu M, Bellas B, Fernandez A, Ferrandiz J, Giraldez M, Gonzalo V, Jover R, Quintero E, Alonso-Coello P, Bonfill X, Lanas A, Piñol V, Piqué J. [Clinical practice guideline. Prevention of colorectal cancer. 2009 update. Asociación Española de Gastroenterología. Gastroenterol Hepatol. 2009; 32:717.e1-58.

Winawer SJ, Zauber AG, Fletcher RH, Stillman JS, O'Brien MJ, Levin B, Smith RA, Lieberman DA, Burt RW, Levin TR, Bond $\mathbb{J H}$, Brooks D, Byers T, Hyman N, Kirk L, Thorson A, Simmang C, Johnson D, Rex DK; US Multi-Society Task Force on Colorectal Cancer; American Cancer Society. Guidelines for colonoscopy surveillance after polypectomy: a consensus update by the US Multi-Society Task Force on Colorectal Cancer and the American Cancer Society. Gastroenterology 2006;130:1872-85.

Rex DK, Johnson DA, Anderson JC, Schoenfeld PS, Burke CA, Inadomi JM; American College of Gastroenterology. American College of Gastroenterology guidelines for colorectal cancer screening 2009 [corrected]. Am JGastroenterol. 2009; 104:739-50.

Levin B, Lieberman DA, McFarland B, Andrews KS, Brooks D, Bond J, Dash C, Giardiello FM, Glick S, Johnson D, Johnson CD, Levin TR, Pickhardt PJ, Rex DK, Smith RA, Thorson A, Winawer SJ; American Cancer Society Colorectal Cancer Advisory Group; US Multi-Society Task Force; American College of Radiology Colon Cancer Committee. Screening and surveillance for the early detection of colorectal cancer and adenomatous polyps, 2008: a joint guideline from the American Cancer Society, the US Multi-Society Task Force on Colorectal Cancer, and the American College of Radiology. Gastroenterology. 2008; 34 :1570-95.

Zauber AG. Cost-effectiveness of colonoscopy. Gastrointest Endosc Clin N Am. 2010; 20: 751-70. 


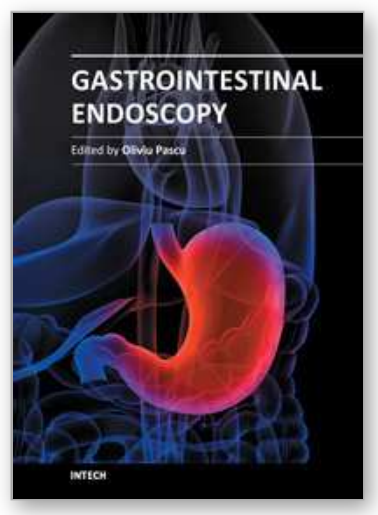

\author{
Gastrointestinal Endoscopy \\ Edited by Prof. Oliviu Pascu
}

ISBN 978-953-307-385-9

Hard cover, 272 pages

Publisher InTech

Published online 19, July, 2011

Published in print edition July, 2011

Endoscopy has had a major impact in the development of modern gastroenterology. By using different data it provided a better understanding of pathogenic mechanisms, described new entities and changed diagnostic and therapeutic strategies. Meanwhile, taking advantage of many technical advances, endoscopy has had a developed spectacularly. Video-endoscopes, magnification, confocal and narrow-band imaging endoscopes, endoscopic ultrasounds and enteroscopes emerged. Moreover, endoscopy has surpassed its function as an examination tool and it became a rapid and efficient therapeutic tool of low invasiveness. InTech Open Access Publisher selected several known names from all continents and countries with different levels of development. Multiple specific points of view, with respect to different origins of the authors were presented together with various topics regarding diagnostic or therapeutic endoscopy. This book represents a valuable tool for formation and continuous medical education in endoscopy considering the performances or technical possibilities in different parts of the world.

\title{
How to reference
}

In order to correctly reference this scholarly work, feel free to copy and paste the following:

David Martinez Ares and Pamela Estévez Boullosa (2011). The Role of Colonoscopy in the Prevention of Colon and Rectal Cancer, Gastrointestinal Endoscopy, Prof. Oliviu Pascu (Ed.), ISBN: 978-953-307-385-9, InTech, Available from: http://www.intechopen.com/books/gastrointestinal-endoscopy/the-role-of-colonoscopyin-the-prevention-of-colon-and-rectal-cancer

\section{INTECH}

open science | open minds

\section{InTech Europe}

University Campus STeP Ri

Slavka Krautzeka 83/A

51000 Rijeka, Croatia

Phone: +385 (51) 770447

Fax: +385 (51) 686166

www.intechopen.com

\section{InTech China}

Unit 405, Office Block, Hotel Equatorial Shanghai

No.65, Yan An Road (West), Shanghai, 200040, China

中国上海市延安西路65号上海国际贵都大饭店办公楼 405 单元

Phone: +86-21-62489820

Fax: $+86-21-62489821$ 
(C) 2011 The Author(s). Licensee IntechOpen. This is an open access article distributed under the terms of the Creative Commons Attribution 3.0 License, which permits unrestricted use, distribution, and reproduction in any medium, provided the original work is properly cited. 